\title{
EL CENTRO DE ESTUDIOS SOBRE LA MEMORIA EDUCATIVA (CEME) DE LA UNIVERSIDAD DE MURCIA Y LA INVESTIGACIÓN EN HISTORIA DE LA EDUCACIÓN MATEMÁTICA
}

\author{
The Centro de Estudios sore la Memoria Educativa (CEME) \\ of the University of Murcia and the research in the History \\ of Mathematical Education
}

\section{Dolores Carrillo Gallego ${ }^{\alpha}$, Pedro Luis Moreno Martínez ${ }^{\beta}$ y Encarna Sánchez-Jiménez}

Fecha de recepción: 29/09/2019 • Fecha de aceptación: 27/10/2019

Resumen: El Centro de Estudios sobre la Memoria Educativa de la Universidad de Murcia (CEME) se creó en 2009 y, como se afirma en su web (www.um.es/web/ceme), "pretende fomentar la salvaguarda, el estudio y la difusión de la memoria y el patrimonio histórico-educativo de las instituciones educativas de la Región de Murcia».

Se trata de una estructura en la que se integra profesorado de la Universidad de Murcia, de diferentes Áreas de Conocimiento, fundamentalmente de Historia de la Educación y de Didácticas específicas. En este documento se presentan los objetivos y realizaciones del CEME, especialmente los relacionados con su programa investigador.

Dentro del CEME, uno de sus colectivos proviene del ámbito de la Didáctica de las Matemáticas, y sus intereses investigadores se orientan hacia

\footnotetext{
a Departamento de Didáctica de las Ciencias Matemáticas y Sociales. Facultad de Educación. Universidad de Murcia. Campus universitario de Espinardo, 30100 Murcia. España. carrillo@um.es (D) http://orcid.org/0000-0002-5170-2550

B Departamento de Teoría e Historia de la Educación. Facultad de Educación. Universidad de Murcia. Campus universitario de Espinardo, 30100 Murcia. España. plmoreno@um.es (D) https://orcid. org/0000-0002-1936-7078

v Departamento de Didáctica de las Ciencias Matemáticas y Sociales. Facultad de Educación. Universidad de Murcia. Campus universitario de Espinardo, 30100 Murcia. España. esanchez@um.es (D) https://orcid.org/0000-0001-5689-366X
}

Cómo citar este artículo: Carrillo Gallego, Dolores, Pedro Luis Moreno Martínez y Encarna Sánchez-Jiménez. «El Centro de Estudios sobre la Memoria Educativa (CEME) de la Universidad de Murcia y la investigación en historia de la educación matemática». Historia y Memoria de la Educación 11 (2020): 615-646 
la Historia de la Educación Matemática (HEM). Un objetivo de este documento es presentar algunos de los trabajos realizados, valorando la contribución del CEME a sus investigaciones y describir las líneas de actuación que este grupo está desarrollando en el ámbito de la HEM.

Palabras clave: Centro de Estudios sobre la Memoria Educativa (CEME); Historia de la Educación Matemática; Memoria educativa; Patrimonio histórico-educativo.

Abstract. The CEME was created in 2009 with the aim of promoting the preservation, study and dissemination of the memory and historical-educational heritage of educational institutions in the Región de Murcia, as is explained on the CEME website (www.um.es/web/ceme).

Its structure brings together professors from the University of Murcia belonging to different areas of knowledge, mainly relating to the History of Education and, more specifically, to Didactics. This document presents the objectives and achievements of CEME, especially those related to its research programme.

One of the CEME groups comes from the field of Didactics of Mathematics, and its research interests are oriented towards the History of Mathematical Education (known in Spanish as HEM). An objective of this document is to present some of the work carried out so far, evaluating the contribution of CEME to its research and describing the lines of action that this group is developing in the field of HEM.

KeyWords: CEME; History of Mathematical Education; Educational Memory; Historical Educational Heritage.

\section{EL CENTRO DE ESTUDIOS SOBRE LA MEMORIA EDUCATIVA (CEME): ORÍGENES, CONFIGURACIÓN, OBJETIVOS \\ Y TRAYECTORIA}

Tras las primeras tentativas fundacionales, iniciadas a comienzos de 2006, el Centro de Estudios sobre la Memoria Educativa de la Universidad de Murcia (CEME) sería creado oficialmente por acuerdo del Consejo de Gobierno de dicha Universidad el 2 de abril de 2009. Su emergencia se llevaba a cabo en un momento en el que la memoria y el patrimonio cultural e histórico estaban de palpitante actualidad dentro y fuera de nuestras fronteras.

Su proceso de gestación estuvo asociado, entre otras causas de carácter general, al progresivo reconocimiento académico, cultural y social 
que la memoria y el patrimonio histórico-educativo venían experimentando tanto en el contexto internacional como de nuestro propio país en los últimos años. Una etapa muy prolífica, en plena efervescencia durante la primera década del siglo XXI, que favorecería y se vería estimulada, entre otros hitos, en nuestro caso, por: la proliferación de exposiciones pedagógicas; el creciente impulso del museísmo pedagógico; la constitución de la Sociedad Española para el Estudio del Patrimonio Histórico-Educativo (SEPHE) en 2003; la gestación de redes nacionales como la Asociación nacional para la defensa del patrimonio de los Institutos históricos (ANDPIH) en 2007; la promoción de proyectos de investigación desde las universidades; la emergencia de entidades orientadas a la investigación y difusión del conocimiento como el Centro Internacional de la Cultura Escolar en Berlanga de Duero (Soria); la edición de publicaciones científicas, el lanzamiento de Cabás en 2009, la primera revista digital especializada sobre patrimonio histórico-educativo; la celebración de encuentros, seminarios, reuniones técnicas y congresos científicos nacionales e internacionales, etc. Asimismo, su creación aparecía indisociablemente unida a la dilatada trayectoria académica de sus promotores relacionada con el estudio y la difusión del patrimonio histórico-educativo reflejada, por ejemplo, en la dirección y/o participación en proyectos de investigación, la organización en curso del Museo Virtual de Historia de la Educación (MUVHE), la intervención en congresos, jornadas y seminarios nacionales e internacionales, la publicación de trabajos científicos, el uso del patrimonio educativo como recurso didáctico, etc. ${ }^{1}$

El CEME surgía como una estructura supradepartamental y multidisciplinar, integrada por profesorado e investigadores de distintas áreas de conocimiento. Sus documentos fundacionales establecían entre sus principales finalidades el fomento, la salvaguarda, el estudio, la formación y la difusión de la memoria y el patrimonio histórico-educativo de las instituciones educativas, en general, y de la Región de Murcia, en particular. El Centro pretendía ser desde su gestación, en primer lugar, un espacio abierto al servicio de las funciones docentes del profesorado de la Facultad de Educación en el que estaba radicado y la formación de

\footnotetext{
1 Pedro Luis Moreno Martínez, «Memoria escolar y patrimonio educativo», en Educación, historia y sociedad. El legado historiográfico de Antonio Viñao, ed. Pedro L. Moreno Martínez (Valencia: Tirant, 2018), 408-415.
} 
sus graduados y postgraduados; en segundo lugar, constituir un medio para fomentar, a partir de sus fondos, la investigación histórico-educativa acerca de las instituciones y las prácticas educativas y la memoria de sus protagonistas, así como, en tercer lugar, recuperar, proteger y conservar el patrimonio histórico-educativo regional, un legado de indudable valor cultural, histórico y educativo. Como Antonio Viñao mencionaría, el CEME nacía como «una aventura museística, académica y científica».2

\section{Líneas de actuación prioritarias}

A tenor de las finalidades y los objetivos planteados en sus documentos fundacionales y programáticos, la trayectoria del Centro se ha vertebrado hasta el presente en torno a cuatro líneas generales de actuación prioritarias.

La primera de ellas, sobre la que de algún aspecto esencial profundizaremos a continuación, ha comprendido las actividades de carácter científico derivadas, principalmente, de: la promoción y realización de proyectos de investigación sobre diferentes vertientes de la cultura material e inmaterial de las instituciones educativas y sus protagonistas; la colaboración con grupos de investigación procedentes de otras universidades e instituciones españolas y extranjeras; la participación y organización de coloquios y reuniones científicas nacionales e internacionales, ${ }^{3}$ la dirección de tesis doctorales y otros trabajos académicos, de los que ha quedado constancia detallada en sus Memorias. ${ }^{4}$

\footnotetext{
2 Antonio Viñao, «El MUVHE y el CEME como pre-texto: reflexiones sobre la protección, conservación, estudio y difusión del patrimonio histórico-educativo», en Patrimonio y Etnografía de la escuela en España y Portugal durante el siglo XX, eds. Pedro L. Moreno Martínez y Ana Sebastián Vicente (Murcia: Sociedad Española para el Estudio del Patrimonio Histórico-Educativo (SEPHE) y Centro de Estudios sobre la Memoria Educativa (CEME) de la Universidad de Murcia, 2012), 639.

${ }^{3}$ Indiquemos, a título de ejemplo, la organización conjunta con la Sociedad Española para el Estudio del Patrimonio Histórico-Educativo (SEPHE) de «Las V Jornadas Científicas de la SEPHE y el III Foro Ibérico de Museísmo Pedagógico», celebrados en Murcia, del 21 al 23 de noviembre de 2012 (Pedro L. Moreno Martínez, «Las Jornadas Científicas de la Sociedad Española para el Estudio del Patrimonio Histórico-Educativo (SEPHE) y el avance del conocimiento", en Memoria de la educación. El legado pedagógico de Julio Ruiz, Berrio, ed. Carmen Colmenar y Teresa Rabazas (Madrid: Biblioteca Nueva, 2015), 281-303).

${ }^{4}$ Pueden verse en la página Web del CEME, en http://www.um.es/web/ceme/ (consultada el 5-082019).
} 
Una segunda línea de actuación ha abarcado las actividades de carácter académico y formativo tendentes a colaborar en la formación inicial y sensibilización de los estudiantes de Grados y Másteres impartidos en la Facultad de Educación de la Universidad de Murcia del valor cultural, etnográfico, histórico y educativo que representa el patrimonio educativo.

La salvaguarda del patrimonio histórico-educativo ha venido siendo su tercer foco de atención. El Centro cuenta con un rico legado de materiales didáctico-científicos procedentes de los gabinetes de Historia Natural y Física y Química de la antigua Escuela Normal de Murcia formado, principalmente, por animales naturalizados, láminas y modelos, instrumentos y aparatos y materiales para la enseñanza de diferentes disciplinas datados desde finales del siglo XIX. Más allá de dicha colección histórica, el CEME ha ido engrosando y diversificando sus fondos a partir de aquellos existentes en la Facultad de Educación, de donaciones y cesiones procedentes, principalmente, de centros educativos y docentes, así como por medio de adquisiciones. En la actualidad el CEME dispone entre sus principales colecciones con las de manuales escolares, cuadernos escolares, catálogos comerciales de material de enseñanza, de fotografías y tarjetas postales de imágenes escolares, un fondo sobre la memoria de los docentes que, entre otras iniciativas, se ha concretado, hasta el momento, en la creación de la «Colección del CEME de archivos personales de antiguos docentes», ubicada en el Archivo Universitario de Murcia, una sección de documentos audiovisuales, producidos en colaboración la Unidad de Apoyo Multimedia TvUM, consistentes en la realización de grabaciones de grupos de renovación pedagógica o del largometraje de cine documental titulado «La memoria de las manos. Ecos del legado pedagógico de C. Freinet en Murcia».

La cuarta línea de actuación engloba las actividades de carácter museográfico. El CEME dispone de una sala de exposiciones ubicada en la Facultad de Educación que alberga la mayor parte de los fondos custodiados agrupados por colecciones. En esta parcela hay que destacar, la realización de exposiciones propias, vinculadas a los proyectos de investigación efectuados. ${ }^{5}$

\footnotetext{
${ }^{5}$ Aproximaciones generales al desarrollo de tales líneas de actuación pueden consultarse en Pedro L. Moreno Martínez, «El Centro de Estudios sobre la Memoria Educativa (CEME) de la
} 


\section{Hacia un balance historiográfico del programa investigador}

Las líneas maestras del programa investigador desarrollado por el CEME a lo largo de sus primeros diez años de existencia han estado dirigidas a la consecución de sus finalidades y objetivos. Unas actividades orientadas, fundamentalmente, como se ha mencionado, al estudio y difusión de la memoria y el patrimonio histórico-educativo, a fomentar, a partir de sus fondos, la investigación histórico-educativa acerca de las instituciones y las prácticas educativas y la memoria de sus protagonistas.

Una de las columnas vertebrales de la investigación desarrollada publicada, específicamente asociada con tales finalidades, ha girado en torno a la cultura material de las instituciones educativas. Un campo de estudio cuyos primeros pasos comenzaron a generarse con antelación, o de forma paralela, al proceso de gestación del CEME. Fueron los casos de los trabajos derivados de los proyectos de investigación aprobados, el primero, por el Ministerio de Ciencia y Tecnología titulado «La cultura material de las instituciones educativas en la España del siglo XX: arquitectura y mobiliario escolares y material científico-pedagógico» (referencia: SEJ2004-07268/EDUC), efectuado entre 2004 y 2007 y, el segundo, por el Ministerio de Educación y Ciencia, denominado «El patrimonio cultural de las instituciones educativas en la España contemporánea (siglos XIX-XXI)» (referencia: SEJ200766165/EDUC), llevado a cabo de 2007 a 2010. La finalidad principal afín a grandes rasgos a ambos proyectos estribaba en el estudio de determinadas vertientes de la cultura material de las instituciones educativas en nuestro país, unos temas que han continuado manteniendo la atención de sus componentes, con mayor o menor intensidad, hasta

Universidad de Murcia: una aventura académica en curso", Cabás - Revista digital sobre el Patrimonio Histórico-Educativo 14 (2015): 173-187, URL: http://revista.muesca.es/centrosphe14/351-ceme (consultado el 3-08-2019); Moreno, "Memoria escolar y patrimonio educativo», 412-415, o en la página Web del CEME, alojada en la URL de la Universidad de Murcia, http://www.um.es/web/ ceme/ (consultada el 3-08-2019). 


\title{
el presente. Nos referimos al estudio de los espacios, ${ }^{6}$ el mobiliario es- colar $^{7}$ y el material científico y pedagógico. ${ }^{8}$
}

\author{
Una segunda línea de trabajo ha guardado relación con la emergen- \\ cia y desarrollo de la memoria como objeto de investigación histórica. El \\ análisis histórico mostraba, entre otras cuestiones, las potencialidades
}

\begin{abstract}
${ }^{6}$ V. gr., Antonio Viñao, «The School Head's Office as Territory and Place: location and physical layout in the first Spanish graded schools», en Materialities of Schooling. Design-Techology - Objects - Routines, eds. Martin Lawn y António Nóvoa (Oxford: Symposium Books, 2005), 47-70; Antonio Viñao, «Templos de la patria, templos del saber. Los espacios de la escuela y la arquitectura escolar», en Historia ilustrada de la escuela en España. Dos siglos de perspectiva histórica, dir. Agustín Escolano (Madrid: Fundación Germán Sánchez Ruipérez, 2006), 47-71; Antonio Viñao, «El espacio escolar: viejas cuestiones, nuevos escenarios», en Historia ilustrada de la escuela en España. Dos siglos de perspectiva histórica, dir. Agustín Escolano (Madrid: Fundación Germán Sánchez Ruipérez, 2006), 289-308; Antonio Viñao, «La escuela y sus escenarios en la España del siglo XX: el espacio y la arquitectura escolar», en La escuela y sus escenarios, eds. Juan Gómez Fernández, Gloria Espigado Tocino y Miguel Beas Miranda (El Puerto de Santa María: Concejalía de Cultura del Ayuntamiento de El Puerto de Santa María, 2007), 9-36; Pedro L. Moreno Martínez, «El aula en el recuerdo: biografía, memoria y cultura material de la escuela primaria en España, 1900-1970», en Museos Pedagógicos. La memoria recuperada, ed. V. Juan (Huesca: Museo Pedagógico de Aragón, 2008), 95-108; Antonio Viñao, «El espacio escolar ¿Cómo abordar un objeto polifacético y multiforme?», en Espacios y patrimonio histórico-educativo, coords. Paulí Dávila Balsera y Luis $\mathrm{M}^{\mathrm{a}}$ Naya Garmendia (Donostia: Erein, 2016), 25-59; Carmen M. Cerdá Mondéjar, «Sobre la celebración de la Fiesta del Árbol en la Región de Murcia: espacio de propaganda política o reflejo de valores educativos», en Espacios y patrimonio histórico-educativo, coords. Paulí Dávila Balsera y Luis $\mathrm{M}^{\mathrm{a}}$ Naya Garmendia (Donostia: Erein, 2016), 541-554; Ana Sebastián Vicente, «Los espacios educativos en la educación de personas adultas. Una aproximación a través de las imágenes de los cuadernos escolares», en Espacios y patrimonio histórico-educativo, coords. Paulí Dávila Balsera y Luis $\mathrm{M}^{\mathrm{a}}$ Naya Garmendia (Donostia: Erein, 2016), 1.101-1.114; J. Damián López Martínez, y Luisa López Banet, «Cotos escolares: espacios educativos para la enseñanza de las ciencias en la escuela española del siglo XX», Bordón 69, no. 3 (2017), 161-174.
\end{abstract}

7 Pedro L. Moreno Martínez, «El mobiliario escolar en los catálogos de material de enseñanza: consideraciones metodológicas», en La infancia en la Historia: espacios y representaciones, coords. Paulí Dávila y Luis M. ${ }^{a}$ Naya (Donostia: Erein, 2005, 2 t., t. I), 342-355; Pedro L. Moreno Martínez, «History of School Desk Development in Terms of Hygiene and Pedagogy in Spain (1838-1936)», en Materialities of Schooling. Design - Techology - Objects - Routines, eds. Martin Lawn y António Nóvoa (Oxford: Symposium Books, 2005), 71-95; Pedro L. Moreno Martínez, «The Hygienist Movement and the Modernization of Education in Spain», Paedagogica Historica. International Journal of the History of Education 42, no. 6 (2006): 793-815.

8 Véanse, por ejemplo, José Mariano Bernal Martínez y José Damián López Martínez, «La Junta para Ampliación de Estudios (JAE) y la enseñanza de la ciencia para todos en España», Revista de Educación, número extraordinario (2007): 215-239; J. Mariano Bernal Martínez y J. Damián López Martínez, «Los museos educativos y el material científico-pedagógico construido en la escuela», en La cultura material de la escuela. En el centenario de la Junta para Ampliación de Estudios, 1907-2007, ed. Agustín Escolano Benito (Berlanga de Duero: Centro Internacional de la Cultura Escolar, 2007), 155-168, Dolores Carrillo Gallego y Encarna Sánchez Jiménez, «Propuestas de uso de los instrumentos de dibujo para la enseñanza de la geometría en la Edad de Plata», en Pedagogía museística. Prácticas, usos didácticos e investigación del patrimonio educativo, coords. A. Badanelli, M. Poveda Sanz y C. Rodríguez, (Madrid: Universidad Complutense de Madrid, 2014). 
hermenéuticas que este nuevo objeto de estudio brindaba para la comprensión del pasado, la variedad de fuentes y recursos metodológicos disponibles, así como la pluralidad y diversidad de memorias existentes. Un "giro memorialístico» que también alcanzaría a la historiografía educativa. En palabras de Juri Meda y Antonio Viñao, uno de los pioneros de dicho campo en nuestro país, ${ }^{9}$ al concepto "memoria escolar» cabía atribuirle dos sentidos netamente diferenciados: "por un lado, la memoria escolar como forma individual de reflexión sobre su propia experiencia escolar, así como de reconstrucción del yo; por otro, como práctica individual, colectiva y/o pública de conmemoración de un pasado escolar común ». ${ }^{10}$ La primera modalidad nos remite básicamente a la reconstrucción personal de la memoria de la escuela llevada a cabo a través de una amplia pléyade de relatos autobiográficos materiales - tales como diarios, autobiografías, correspondencia, memorias, etc.-, o inmateriales - testimonios orales, entrevistas biográficas, historias de vida, etc.- - La segunda modalidad nos sitúa en una dimensión distinta alejada de las diversas formas autobiográficas del recuerdo para aproximarnos a los usos efectuados de la memoria de la escuela como proceso histórico en la construcción intencionada de imaginarios colectivos del pasado escolar determinados o condicionados por las políticas de la memoria. Un campo historiográfico en el que, como en la anterior línea apuntada, algunos miembros del CEME ya venían ocupándose, en las dos modalidades indicadas, antes de la aprobación oficial del mismo y continuaron cultivándolo hasta el presente. ${ }^{11}$

\footnotetext{
${ }_{9}$ Para una compresión más detallada de las aportaciones del profesor Viñao a este campo historiográfico véanse Aida Terrón Bañuelos, «El profesorado. Autobiografías, memorias y diarios», en Educación, historia y sociedad. El legado historiográfico de Antonio Viñao, ed. Pedro L. Moreno Martínez (Valencia: Tirant, 2018), 355-383, y Moreno, «Memoria escolar y patrimonio educativo», 386-395.

10 Juri Meda y Antonio Viñao, «School Memory: Historiographical Balance and Heuristcs Perspectives», en School Memories. New Trends in the History of Education, eds. Cristina Yanes-Cabrera, Juri Meda y Antonio Viñao (New York: Springer, 2017), 2.

11 Véanse, v. gr., Antonio Viñao, «La memoria escolar: restos y huellas, recuerdos y olvidos», Annali di Storia dell'Educazione e delle Istituzioni Scholastiche 12 (2005): 19-33; Antonio Viñao, "Memoria escolar y Guerra Civil. Autobiografías, memorias y diarios de maestros y maestras», Cultura Escrita \& Sociedad 4, (2007): 171-202; Antonio Viñao, «Ayer y hoy de la educación en España: memorias y desmemorias», en Lecciones contra el olvido. Memoria de la educación y educación de la memoria, coord. Carlos Lomas (Barcelona: Octaedro, 2011), 23-60; Antonio Viñao, «Teacher's Egodocuments as a Source of Classroom History. The Case of Autobiographies, Memoirs and Diaries», en The Black Box of Schooling. A Cultural History of the Classroom, eds. Sjaak Braster, Ian Grosvenor y M ${ }^{\mathrm{a}}$ del Mar del Pozo (Bruxelles: P.I.E. Peter Lang, 2011), 141-157; J. Mariano Bernal Martínez y J. Pedro Marín Murcia, «José Loustau y la Universidad de Murcia (1916-1965): el desarrollo de la competencia
} 
En esta línea habría que destacar el proyecto de investigación titulado «El patrimonio histórico-educativo en la Región de Murcia. La memoria de los docentes»(11903/PHCS/09), financiado por la Fundación Séneca. Agencia Regional de Ciencia y Tecnología de la Región de Murcia, llevado a cabo desde 2010 a 2014. Entre sus principales logros contaría con la publicación de más de medio centenar de trabajos plasmados en libros, capítulos de libro, números monográficos, ediciones y artículos, la presentación de medio centenar de comunicaciones y ponencias en congresos, jornadas y coloquios nacionales e internacionales, la organización de varias exposiciones presenciales y virtuales, ${ }^{12}$ la realización de grabaciones

profesional y la promoción de la educación científica», en Arte y oficio de enseñar. Dos siglos de perspectiva histórica, ed. P. Celada Perandones (El Burgo de Osma: Sociedad Española de Historia de la Educación, Universidad de Valladolid y Centro Internacional de la Cultura Escolar, 2011, 2 vols., vol. I), 287-294; Ma Ángeles Delgado Martínez y J. Damián López Martínez, «Dr. Camps (Margarita Comas): una maestra en el exilio», en Arte y oficio de enseñar. Dos siglos de perspectiva histórica, ed. Pablo Celada Perandones (El Burgo de Osma: Sociedad Española de Historia de la Educación, Universidad de Valladolid y Centro Internacional de la Cultura Escolar, 2011, 2 vols., vol. I), 605-614; Pedro L. Moreno, Félix Martí Alpera (1875-1946): un maestro y la escuela de su tiempo (Murcia: Ediciones de la Universidad de Murcia, 2010); Pedro L. Moreno, "Las Memorias de Félix Martí Alpera», en Memorias, ed. Félix Martí Alpera (Murcia: Ediciones de la Universidad de Murcia, 2011), I-XXXII (estudio introductorio); $M^{\mathrm{a}}$ Ángeles Delgado Martínez y J. Damián López Martínez, «Los diarios del alumnado de la Escuela Normal de Magisterio de Murcia (1931-1933) como muestra de la práctica y el quehacer diario en las clases de Primitiva López», en Patrimonio y etnografía de la escuela en España y Portugal durante el siglo XX, eds. Pedro L. Moreno Martínez y Ana Sebastián Vicente (Murcia: SEPHE-CEME, 2012), 419-434; J. Damián López Martínez (Coord.), Las ciencias en la escuela. El material científico y pedagógico de la Escuela Normal de Murcia (Murcia: Editum, 2012); Kira Mahamud y M. ${ }^{a}$ José Martínez Ruiz-Funes, «Reconstructing the life histories of Spanish primary school teachers: a novel approach for the study of the teaching profession and school culture», History of Education 46, no. 3 (2014): 793-819; José Damián López Martínez, Aurelio Rodríguez Charentón, un maestro en el olvido (Murcia: Editum, 2014); Nicolás Martínez-Valcárcel (dir.), La construcción de los recuerdos escolares de Historia de España en Bachillerato (1993-2013). Análisis, interpretación y poder de cambio de los testimonios de profesores y alumnos (Valencia: Nau Llibres, 2014); Dolores Carrillo Gallego y Encarna Sánchez Jiménez, «Aprender matemáticas jugando: la propuesta educativa de Eyaralar», en La cultura material de la escuela. En el centenario de la Junta para la Ampliación de Estudios, 1907-2007, ed. Agustín Escolano, 183-194 (Berlanga de Duero (Soria): CEINCE, 2007); Dolores Carrillo Gallego, "Vallejo y la iniciación aritmética en las escuelas», en José Mariano Vallejo, el matemático ilustrado. Una mirada desde la educación matemática, eds. Alexander Maz, Manuel Torralbo y Luís Rico (Córdoba: Servicio de Publicaciones de la Universidad de Córdoba, 2006), 25-47; Encarna Sánchez Jiménez, «La resolución de problemas: aportaciones de Aurelio Rodríguez Charentón», en Arte y oficio de enseñar. Dos siglos de perspectiva histórica, ed. Pablo Celada Perandones (El Burgo de Osma: Sociedad Española de Historia de la Educación, Universidad de Valladolid y Centro Internacional de la Cultura Escolar, 2011, 2 vols., vol. II), 507-516.

12 Se trataba de las exposiciones tituladas: «Félix Martí Alpera (1875-1946): un maestro y la escuela de su tiempo» (Murcia, 2010; Cartagena, 2011; Barcelona, 2012); «Los materiales de Educación Infantil del siglo XIX en un espacio del siglo XXI. Los Dones de Froebel» (Murcia, 2013); «Aurelio Rodríguez Charentón (1895-1962): un aguileño y la renovación pedagógica en España» (Águilas, 2014; Murcia, 2014); o la Exposición virtual «Margalida Comas Camps (1892-1972)». Esta exposición virtual, así como a las versiones on line de las muestras relativas a Félix Martí Alpera y Aurelio 
de testimonios de docentes involucrados en los procesos de renovación pedagógica llevados a cabo en la Región de Murcia desde los inicios de la década de los 70 hasta finales de los $80 .{ }^{13}$ En esta línea de producción audiovisual hay que destacar la producción, por parte de la Universidad de Murcia, del documental «La Memoria de las manos. Ecos del legado pedagógico de C. Freinet en Murcia». ${ }^{14}$

Una tercera línea de investigación desarrollada ha tenido por objeto la reflexión general en torno a las relaciones e interacciones existentes entre patrimonio y educación, uno de los temas del ámbito de la historia de la educación que habían experimentado un mayor desarrollo en las dos últimas décadas. ${ }^{15}$

Durante las últimas décadas del pasado siglo XX asistimos a un proceso en el contexto internacional en el que el museísmo pedagógico transitó del resurgimiento a la eclosión de las instituciones museísticas vinculadas al mundo de la educación. Las universidades han desempeñado en esta dinámica, en nuestro país, un papel crucial en el impulso y desarrollo de programas de investigación, salvaguarda y difusión del patrimonio histórico-educativo, en el proceso de recuperación, impulso, orientación y proyección del movimiento museístico pedagógico y la promoción, entre otras tentativas, de iniciativas museísticas propias. La cuarta línea de investigación acometida desde el CEME ha respondido plenamente a esta tendencia. Por una parte, la existencia misma del

Rodríguez Charentón, pueden visitarse en el Museo Virtual de Historia de la Educación (MUVHE), en la URL https://www.um.es/muvhe/ (consultado el 5-8-2019).

13 Pueden verse en la página Web del CEME, en http://www.um.es/web/ceme/ (consultada el 5-082019).

${ }_{14}$ Alfonso Burgos-Risco y María J. Martínez-Ruiz, «La memoria de las manos. La realización de un documental de historia de la educación», Arte, Individuo y Sociedad, 31, no. 2 (2019): 345-359.

15 Pedro L. Moreno Martínez, «La modernización de la cultura material de la escuela pública en España, 1882-1936», en La cultura material de la escuela. En el centenario de la Junta para Ampliación de Estudios, 1907-2007, ed. Agustín Escolano Benito (Berlanga de Duero: Centro Internacional de la Cultura Escolar, 2007), 45-74; Isabel Carrillo, Eulàlia Colleldemont y Pedro L. Moreno, «El patrimoni educatiu, element d'una pedagogia cultural i ciutadana», Temps d'Educació 35 (2008): 277-290; Pedro L. Moreno, «La Historia de la educación como disciplina y campo de investigación: renovación historiográfica, patrimonio y educación», en El largo camino hacia una educación inclusiva. Aportaciones desde la Historia de la Educación, coord. Reyes Berruezo (Pamplona: Universidad Pública de Navarra, 2009), 141-151; Pedro L. Moreno Martínez, «Presentación», Educatio Siglo XXI 28, no. 2 (2010): 9-15; Antonio Viñao, «Memoria, patrimonio y educación», Educatio Siglo XXI 28, no. 2 (2010): 17-42; Antonio Viñao, «El patrimonio histórico-educativo: memoria, nostalgia y estudio», Con-Ciencia Social 15 (2011): 141-147. 
CEME, o el Museo Virtual de Historia de la Educación (MUVHE) estrechamente relacionado al mismo, son consecuencias palpables de las actuaciones emprendidas en este campo. Asimismo, el museísmo pedagógico también ha constituido un ámbito de investigación y reflexión referido tanto a entidades emblemáticas históricas ${ }^{16}$ como, principalmente, las actuales y dentro de ellas, muy particularmente, sobre el CEME y el MUVHE. ${ }^{17}$

Una nueva línea de investigación ha centrado su atención en el estudio del patrimonio material e intangible como recurso educativo desde una doble perspectiva. Por una parte, por sus potencialidades como objeto de investigación histórica para analizar las culturas escolares, la evolución de las disciplinas escolares y su código disciplinar, aproximarnos a lo que fueron las prácticas educativas pretéritas, estilos de enseñanza y metodologías docentes en el aula, para profundizar en el conocimiento e interpretación del pasado en el ámbito escolar. ${ }^{18}$ Por otra

\footnotetext{
16 Pedro L. Moreno Martínez, «El Museo Pedagógico Nacional y la modernización educativa en España (1882-1941)», en La Institución Libre de Enseñanza y Francisco Giner de los Ríos: nuevas perspectivas. 2. La Institución Libre de Enseñanza y la cultura española, eds. José García Velasco y Antonio Morales Moya (Madrid: Fundación Francisco Giner de los Ríos [Institución Libre de Enseñanza] - Acción Cultural Española, 2012), 458-475; Pedro L. Moreno Martínez, «El Museo Pedagógico Nacional: un laboratorio para la formación del magisterio», en Laboratorio de la Nueva Educación. En el centenario del Instituto-Escuela, ed. Belén Alarcó (Madrid: Fundación Francisco Giner de los Ríos [Institución Libre de Enseñanza], 2019), 408-415.

17 Véanse, por ejemplo, además de los trabajos ya mencionados al respecto, Antonio Viñao, «Historia y educación: memorias, olvidos y silencios (bases para la creación de un centro de memoria educativa)», en Jornada de Homenaje al maestro del Consejo Escolar de la Región de Murcia (Murcia: Consejería de Educación y Cultura, Consejo Escolar, 2005), 69-90; Pedro L. Moreno «Els museus virtuals d'educació com a pedagogia», Butlletí MUVIP 1 (2009): 11-16; M ${ }^{\mathrm{a}}$ Ángeles Delgado Martínez et al., «El material científico del Instituto Local de Lorca (siglo XIX): recuperación y difusión a través del Museo Virtual de Historia de la Educación», en I Encontro Iberoamericano de Museos Pedagóxicos e museólogos da educación. Actas (Santiago de Compostela: Xunta de Galicia, MUPEGA, 2008), 531543; J. Damián López Martínez, «Divulgación de la cultura científica a través del patrimonio histórico-científico del Centro de Estudios sobre la Memoria Educativa», en Memoria, ciudadanía y Museos de educación, coords. Eulalia Colleldemont, Nuria Padrós e Isabel Carrillo (Vic: Universidad de Vic, 2010), 119-130; Pedro L. Moreno Martínez, «El Museo Virtual de Historia de la Educación (MUVHE) y el Centro de Estudios sobre la Memoria Educativa (CEME) de la Universidad de Murcia», en Los Museos Pedagógicos en España. Entre la memoria y la creatividad, coord. Pablo Álvarez Domínguez (Gijón - Sevilla: Trea - Editorial Universidad de Sevilla, 2016), 175-188.
}

18 A título de ejemplo, véanse J. Damián López Martínez, «Francia en el punto de mira: el material científico para la enseñanza de la física y química en los institutos de segunda enseñanza a partir del Plan de 1845», en Influencias francesas en la educación española e iberoamericana (1808-2008), ed. J. M ${ }^{\mathrm{a}}$ Hernández Díaz (Salamanca: Gobalia ediciones Anthema, 2008), 147-159; J. Damián López Martínez y J. Mariano Bernal Martínez, «La Revista de Pedagogía como fuente de información sobre el material científico-didáctico escolar», en Museos pedagógicos. La memoria recuperada, ed. Víctor Juan (Huesca: Gobierno de Aragón-Museo Pedagógico de Aragón, 2008), 351- 366; María José 
parte, por las potencialidades que el patrimonio ofrece como recurso educativo y estrategia didáctica para una educación patrimonial que contribuya a la adquisición y desarrollo de capacidades que generen el conocimiento, la comprensión, el respeto y la conservación del patrimonio. ${ }^{19}$

Por último, aludiremos concisamente al estudio de los fondos existentes en el CEME, así como a las fuentes relacionadas con los mismos, que han constituido una de las arterias de investigación claves. Nos referimos a las colecciones de material científico pedagógico, ${ }^{20}$ manuales

\begin{abstract}
Martínez Ruiz-Funes, «El material froebeliano en España en la segunda mitad del siglo XIX», en Influencias alemanas en la educación española e iberoamericana (1809-2009), ed. J. M ${ }^{\mathrm{a}}$ Hernández Díaz (Salamanca: Globalia ediciones Anatema, 2009), 153-166; Antonio Viñao Frago, «La historia de las disciplinas escolares en España: una revisión con especial atención a la educación secundaria», en Aulas con memoria. Ciencia, educación y patrimonio en los Institutos históricos de Madrid (18371936), eds. Leoncio López Ocón, Santiago Aragón y Mario Pedrazuela (Madrid, CEIMES, CSIC y Comunidad de Madrid, 2012), 265-277; Pedro L. Moreno Martínez, «Rosa Sensat, la cultura material de l'escola i el material d'ensenyament», Temps d'Educació 44 (2013): 77-99, Dolores Carrillo Gallego y Encarna Sánchez Jiménez, «El material de enseñanza en las praxeologías de formación de maestros en España (1920-1936)», en IV Congrès International sur la TAD. (Toulouse: IUFM de l'Academie de Toulouse (France), 2013).
\end{abstract}

19 V. gr., J. Mariano Bernal Martínez, J. Damián López Martínez y Pedro L. Moreno Martínez, «Museos pedagógicos y enseñanza de las ciencias: de las láminas y colecciones a los recursos didácticos virtuales», en I Encontro Iberoamericano de Museos Pedagóxicos e Museólogos da educación. Actas (Santiago de Compostela: Xunta de Galicia, MUPEGA, 2008), 413-425; J. Mariano Bernal Martínez y J. Damián López Martínez, El patrimonio científico de los institutos de enseñanza secundaria. Un recurso didáctico en las Ciencias para el mundo contemporáneo (Madrid: UNED ediciones, 2009); J. Mariano Bernal Martínez, M ${ }^{a}$ Ángeles Delgado Martínez y J. Damián López Martínez, «El patrimonio histórico-científico como recurso didáctico: de las ciencias de laboratorio a las ciencias para la vida», en El largo camino hacia una Educación Inclusiva. La Educación Especial y Social del siglo XIX a nuestros días, coords. Reyes Berruezo Albéniz y Susana Conejero López (Pamplona: Universidad Pública de Navarra, 2009), 605-614; J. Damián López Martínez y J. Mariano Bernal Martínez, «El material de enseñanza como recurso didáctico en la Historia de la Educación», en El Patrimonio histórico-educativo y la enseñanza de la Historia de la Educación (Murcia: Sociedad Española de Historia de la Educación, 2009, 53-92; Ma Ángeles Delgado Martínez et al., El Gabinete de Física del Instituto de Lorca (1864-1883): guía didáctica (Murcia: Servicio de Publicaciones Consejería de Educación, Formación y Empleo de la Región de Murcia, 2010); María José Martínez Ruiz-Funes, Pedro L. Moreno Martínez y Ana Sebastián Vicente, «Los catálogos de material de enseñanza como recurso didáctico», en Genealogía y desarrollo del sistema educativo liberal, ed. Gloria Espigado Tocino et al., (Cádiz: Universidad de Cádiz, 2013), 867-877; José Damián López Martínez et al., «Patrimonio, cultura material e innovación docente: Propuestas y experiencias», Educació i Història: Revista d'Història de l'Educació 26 (2015): 89-120; Nicolás Martínez-Valcárcel y Ramón García, El patrimonio enseñado: plataforma para el desarrollo del turismo responsable. Base de Datos 2013-2014 (Murcia: Diego Marín, 2016).

${ }_{20}$ V. gr., J. Mariano Bernal Martínez y José Pedro Marín Murcia, «El estudio del material científico para el estudio de la Botánica en el CEME», en Patrimonio y etnografía de la escuela en España y Portugal durante el siglo XX, eds. Pedro L. Moreno Martínez y Ana Sebastián Vicente (Murcia: SEPHE-CEME, 2012), 157-166; López, Las ciencias en la escuela; Carrillo y Sánchez, "Propuestas de uso». 
escolares, ${ }^{21}$ cuadernos escolares, ${ }^{22}$ catálogos comerciales de material de enseñanza ${ }^{23}$ o de fotografías y tarjetas postales. ${ }^{24}$ Vinculadas a esta línea de investigación también cabe destacar la organización de tres exposiciones y la publicación de sus catálogos respectivos. ${ }^{25}$

\begin{abstract}
${ }^{21}$ Ana Sebastián Vicente, «Los manuales escolares: cultura material de la escuela y fuente para la historia de la educación. Un análisis de los libros de lectura para adultos neolectores durante las campañas de alfabetización del franquismo», en Museos Pedagógicos. La memoria recuperada, ed. Víctor Juan (Huesca: Museo Pedagógico de Aragón, 2008), 207-220; José Damián López Martínez, «Construir una imagen de la ciencia: las ilustraciones de los libros escolares de lecturas científicas», en Actas del XVIII Coloquio de historia de la Educación. Arte, Literatura y educación, eds. Nuria Padrós, Eulalia Colleldemont y J. Soler (Vic: Servicio de publicaciones de la Universitat de Vic, 2015), 125-138; Antonio Viñao, «El Libro escolar», en Historia de la edición en España 1939-1975, dir. Jesús A. Martínez Martín (Madrid: Marcial Pons Historia, 2015), 681-698; Nicolás Martínez-Valcárcel, «El uso del libro de texto de Historia de España en bachillerato», Revista Historia da Educação 20, no. 50 (2016): 69-93.
\end{abstract}

${ }_{22}$ Véanse, por ejemplo, Antonio Viñao, «Los cuadernos escolares como fuente histórica: aspectos metodológicos e historiográficos», Annali di Storia dell'Educazione e delle Istituzioni Scholastiche 13 (2006): 17-35; Antonio Viñao y María José Martínez Ruiz Funes, «Los cuadernos escolares y el arte de enseñar: el fondo del Centro de Estudios sobre la Memoria Educativa (CEME) de la Universidad de Murcia», en Arte y oficio de enseñar. Dos siglos de perspectiva histórica, ed. Pablo Celada Perandones (El Burgo de Osma: Sociedad Española de Historia de la Educación, Universidad de Valladolid, Centro Internacional de la Cultura Escolar, 2011, 2 vols., vol. I), 245-254; Antonio Viñao Frago, «Balance de la investigación sobre cuadernos escolares en España», en La historia de la cultura escolar en Italia y España: balance y perspectivas, eds. Juri Meda y Ana Badanelli (Macerata: Edizioni Università di Macerata (EUM), 2013), 63-82; J. Damián López Martínez y Mª José Martínez Ruiz-Funes, «Análisis de cuadernos escolares producidos por casas editoriales de ciencias experimentales», en Espacios y patrimonio histórico-educativo, coords. Paulí Dávila y Luis M. a Naya (Donostia: Erein, 2016), 1.053-1.073; Dolores Carrillo Gallego y Encarna Sánchez Jiménez. «El "cálculo vivo" en un cuaderno freinetiano». HISTEMAT 3 no. 3 (2017): 40-54.

${ }^{23}$ V. gr., Pedro L. Moreno Martínez y Ana Sebastián Vicente, «Los catálogos de material de enseñanza y la cultura material de la escuela. La colección del Centro de Estudios sobre la Memoria Educativa (CEME) de la Universidad de Murcia», en Patrimonio y etnografía de la escuela en España y Portugal durante el siglo XX, eds. Pedro L. Moreno Martínez y Ana Sebastián Vicente (Murcia: SEPHE-CEME, 2012), 293-309; Pedro L. Moreno Martínez y José Pedro Marín Murcia, «La casa comercial Cultura y la oferta de Material Pedagógico Moderno en España (1924-1934)», en Pedagogía museística. Prácticas, usos didácticos e investigación del patrimonio educativo, coords. Ana Badanelli, María Poveda Sanz y Carmen Rodríguez (Madrid: Universidad Complutense de Madrid, 2014), 523-531.

${ }^{24}$ Véanse, por ejemplo, Antonio Viñao y $\mathrm{M}^{\mathrm{a}}$ José Martínez Ruiz-Funes, «The illustrated postcards as a tool of construction and reconstruction of the school memory (Spain, 19th-20th century)», en School memories. New trends in the history of education research, en eds. Juri Meda, Cristina Yanes y Antonio Viñao (New York: Springer, 2016), 29-46, y Pedro L. Moreno y Antonio Viñao (coords.), Imagen y educación. Marketing, comercialización, didáctica (España, siglo XX) (Madrid: Morata, 2017.

${ }^{25}$ Se trata de las exposiciones: «Las ciencias en la escuela: el material científico y pedagógico de la Escuela Normal de Murcia» (Murcia, 2012), «Tarjeta postal ilustrada y educación (España, siglos XIXXX)», (Murcia, 2016 y Cartagena, 2017) y «Los cuadernos escolares: entre el texto y la imagen», (Murcia, 2017). De tales exposiciones temporales puede accederse tanto a sus versiones virtuales en la Web del MUVHE, en la URL https://www.um.es/muvhe/ (consultado el 6-8-2019), como a sus catálogos: López, Las ciencias en la escuela; Antonio Viñao, M. ${ }^{a}$ José, Martínez Ruiz-Funes y Pedro L. Moreno Martínez, Tarjeta postal ilustrada y educación (España, siglos XIX-XX) (Murcia: edit.um, 2016), y Dolores Carrillo Gallego, et al., Los cuadernos escolares: entre el texto y la imagen (Murcia: edit.um, 2017). 


\section{EL CEME Y LA HISTORIA DE LA EDUCACIÓN MATEMÁTICA}

Desde su creación, en el CEME se ha integrado profesorado de Didáctica de las Matemáticas con interés por la Historia de la Educación Matemática y su investigación.

Las primeras profesoras que pertenecieron a él formaban parte del grupo de profesores de didácticas específicas que, con la dirección de Antonio Viñao, elaboraron tesis doctorales sobre la Historia de las Disciplinas Escolares. La tesis de Dolores Carrillo Gallego (2005) trataba sobre «La Metodología de la aritmética en los comienzos de las Escuelas Normales (1838-1868) y sus antecedentes», mientras que la de la profesora Encarna Sánchez Jiménez (2015) se titulaba «Las Escuelas Normales y la renovación de la enseñanza de las matemáticas (1909-1936)», ${ }^{26}$ lo que señala una orientación hacia la formación en didáctica de las matemáticas del magisterio y hacia el estudio de las instituciones en las que se realizaba dicha formación y los recursos que se utilizaban.

La integración en el CEME y la influencia de sus primeros directores (Antonio Viñao y Pedro Luis Moreno) propiciaron una visión de la Historia de la Educación Matemática que integra nuevas perspectivas historiográficas, en sintonía con el proyecto de Historia total de Pierre Vilar y la atención a la historia cultural y la historia material de la escuela.

La relación con un centro de memoria educativa ha posibilitado la utilización de fuentes de diverso tipo, de acuerdo con las diferentes perspectivas historiográficas. Como suele ser habitual en estas investigaciones, se han utilizado y analizado los libros de texto, pero también se ha enfatizado la importancia de las instituciones encargadas de la enseñanza de las matemáticas, se han caracterizado dichas instituciones desde el punto de vista legislativo, pero no solo. También se han abordado cuestiones sobre la cultura escolar y la cultura material en dichas instituciones.

Se han estudiado, por tanto, los diversos niveles de la transposición didáctica, hasta el saber enseñado, con incursiones en el saber del

\footnotetext{
26 Dolores Carrillo Gallego, «La Metodología de la aritmética en los comienzos de las Escuelas Normales (1838-1868) y sus antecedentes» (Tesis doctoral, Universidad de Murcia, 2005); Encarna Sánchez Jiménez, «Las Escuelas Normales y la renovación de la enseñanza de las matemáticas (19091936)» (Tesis doctoral, Universidad de Murcia, 2015).
} 
alumno; y esto tanto en lo que se refiere al saber matemático que se estudia en las instituciones de formación del magisterio como en los saberes más específicos de la didáctica de las matemáticas.

Para la realización de estos trabajos se han utilizado los fondos del CEME y de la Biblioteca de Historia de la Educación «Profesor Antonio Viñao». Pero también el CEME se ha enriquecido con los resultados de esas investigaciones para las cuales se han elaborado materiales que se exponen por periodos variables en el CEME y que han pasado a formar parte, en algunos casos, de los fondos de que dispone este centro.

Un ejemplo es la exposición sobre José María Eyaralar, profesor de Matemáticas en Escuelas Normales, titulada «José María Eyaralar Almazán (1890-1942): La renovación en la enseñanza de las matemáticas», que tuvo lugar en la Facultad de Educación en noviembre de 2016, en la que se utilizaron libros, documentos y materiales que fueron recopilados, localizados o adquiridos como fuentes para la elaboración de la tesis de Encarna Sánchez, y cedidos temporalmente al CEME, así como otros materiales didácticos para la enseñanza de la matemática diseñados durante la llamada Edad de Plata y que fueron construidos ex profeso para la exposición. En marzo de 2017 la exposición se ha trasladado a Huesca, a la Facultad de Ciencias Humanas y de la Educación de la Universidad de Zaragoza, con motivo del 150 aniversario de la creación de la Escuela Normal de Maestros de dicha ciudad, y posteriormente se expuso en la Facultad de Matemáticas de la Universidad de Murcia en mayo de ese mismo año, durante las Jornadas del Profesorado: Intercambio de experiencias y buenas prácticas en Educación Matemática, respondiendo a una invitación del Centro de Profesores y Recursos de Murcia.

La Historia de la Educación y la Didáctica de la Matemática convergen cuando se trata de investigar en Historia de la Educación Matemática. En efecto, entrar a fondo en la historia de una disciplina supone un análisis desde la epistemología de dicha disciplina, en este caso las matemáticas, y para ello se requiere el uso de las herramientas propias de la Didáctica de la Matemática. A su vez, este análisis didáctico sería, no solo incompleto, sino también parcial — desde el programa de investigación en el que se sitúan las investigaciones realizadas en esta materia por investigadoras del CEME—, a menos que considere aspectos relativos a la Historia de la educación, que permitan llevar a cabo el estudio 
desde una perspectiva institucional, y de ese modo entender e interpretar la información disponible. Desde esta perspectiva el CEME resulta decisivo por cuanto aporta fondos bibliográficos y otras fuentes de referencia para este tipo de trabajos de investigación.

Un índice de la vinculación del CEME con la investigación en HEM ha sido la organización de IV Congreso Iberoamericano de Historia de la Educación Matemática, que tuvo lugar en la Facultad de Educación de la Universidad de Murcia, en cuyos locales se encuentra el CEME, entre los días 14 a 17 de noviembre de 2017 y la edición de sus actas. ${ }^{27}$

\section{PERSPECTIVAS}

Relacionado con el CEME, se está configurando un grupo de trabajo sobre Historia de la Educación Matemática. Dirigido a ese grupo de personas, en septiembre de 2019, se ha impartido un curso universitario de "Iniciación a la investigación en Historia de la Educación Matemática», dirigido por las profesoras Dolores Carrillo y Encarna Sánchez, en el que intervinieron los profesores Pedro Luis Moreno y Antonio Viñao, de la Universidad de Murcia, y Wagner R. Valente de la Universidad Federal de Sao Paulo (Brasil); al curso asistieron 16 personas, la mayoría profesores de Didáctica de las Matemáticas.

Una de las cuestiones abordadas en el curso fue la problemática de las fuentes en la investigación histórica. En particular, se analizaron las fuentes utilizadas en trabajos de HEM y se valoró la aportación de los fondos del CEME a estos trabajos. Precisamente uno de los factores decisivos en la investigación histórica es la disponibilidad de fuentes primarias. En este sentido el CEME posibilita la consulta de este tipo de fuentes, sobre las que se comentaron, además, las dificultades encontradas a veces para catalogarlas - por ejemplo, para datar con exactitud algunos de los documentos-o la representatividad de las fuentes utilizadas.

Comentamos seguidamente algunas de las perspectivas de trabajo ligadas a los fondos del CEME.

27 Dolores Carrillo, José Manuel Matos, Pedro Luis Moreno, Encarna Sánchez-Jiménez y Wagner R. Valente, IV Congreso Iberoamericano de Historia de la Educación Matemática. Actas. (Murcia -España: Centro de Estudios sobre la Memoria Educativa. Universidad de Murcia, 2018). 
Libros de texto. Dentro de la colección del CEME hay un apartado dedicado a los libros de matemáticas y otro a las enciclopedias escolares. Los libros de texto son una fuente fundamental para investigar en la historia de las disciplinas escolares ya que, si es a partir del análisis de programas y de libros de texto como el investigador puede reconstruir la matemática «a enseñar», son los libros los que permiten indagar en el currículum real, puesto que a través de los textos el investigador puede conocer la transposición didáctica que se ha hecho de los programas ${ }^{28}$ en las instituciones correspondientes. La investigación sobre los sistemas de enseñanza —en particular de la matemática- se apoya por tanto en los textos escolares, entre otras fuentes, para caracterizar dichos sistemas y compararlos. Así, el acopio y la catalogación de este tipo de fondos favorece los estudios comparativos sobre la enseñanza de las matemáticas en periodos históricos relevantes en cuanto a la enseñanza de esta materia y de cara al proceso de constitución de las disciplinas escolares, más concretamente de la metodología de la matemática. Precisamente es en el marco que proporciona la historia de las disciplinas en el que se han de analizar los libros de texto, los cuales se consideran «uno de los instrumentos fundamentales para la determinación y el conocimiento de la evolución del código disciplinar respectivo». ${ }^{29}$

Además, considerados por los investigadores en didáctica de la matemática como parte esencial del entorno profesional del profesor, el análisis de la relación de un profesor con los manuales escolares (y con el resto de la «documentación escolar», esto es, libros para profesores, cuadernos y material complementario, etc.) y del empleo que haga de estos, es un elemento decisivo para conocer el trabajo del profesor, ${ }^{30}$ como se ha puesto de manifiesto en algunos de los trabajos realizados por personal adscrito al CEME. ${ }^{31}$

\footnotetext{
${ }^{28}$ Hamid Chaachoua y Claude Comiti, «L'analyse du rôle des manuels dans l'approche anthropologique», en II Congrés International su la Théorie Antropologique du Didactique (Uzés, 2007), 137-151.

${ }_{29}$ Antonio Viñao, «Historia de las disciplinas, profesionalización docente y formación de profesores: el caso español», Pro-Posiçoes 23 (2012): 116.

${ }^{30}$ Claire Margolinas y Floriane Wozniak, «Usage des manuels dans le travail de l'enseignant: l'enseignement des mathématiques à l'école primaire», Revue des sciences de l'éducation 35, n 2 (2009): 59-82.

31 Sánchez-Jiménez, «Las Escuelas Normales».
} 
Hay que señalar también que en la biblioteca del Área de Didáctica de las Matemáticas existe otro fondo de libros de texto, en proceso de organización, especializado, sobre todo, en obras publicadas en los últimos 50 años, desde la entrada en vigor de la Ley General de Educación de 1970.

Catálogos de material escolar. «Los espacios, los objetos, los útiles y los materiales existentes en las aulas y en otras dependencias escolares no son elementos neutros e inertes, ajenos a los procesos educativos, sino que componen un conjunto de significantes cargados de significado que contribuyen a conformar la intrahistoria de la escuela».32 Los catálogos de material escolar nos informan de los objetos que podían utilizarse en el aula por haber sido fabricados comercialmente; constituyen, por tanto, una aproximación a la cultura material de la escuela.

Entre los catálogos del CEME, hay una colección dedicada al material escolar. Constituyen una valiosa fuente para conocer la cultura material de las instituciones escolares en un momento dado. Con ellos se han realizado estudios sobre su interés como fuente para la HEM, ${ }^{33}$ así como sobre el uso escolar de objetos concretos. ${ }^{34}$ En este momento se están utilizando para estudiar las actividades de enseñanza de las matemáticas en las propuestas de la escuela nueva.

Materiales didácticos. Los materiales didácticos, al igual que el patrimonio material en general, forman parte de la cultura material de la escuela y son, por tanto, otro de los elementos clave para explicar la circulación de las ideas pedagógicas. ${ }^{35}$

\footnotetext{
32 Moreno, «El mobiliario escolar en los catálogos», 342.

33 Dolores Carrillo Gallego, «Los catálogos de material escolar como fuente de la Historia de la Educación Matemática: el caso de los ábacos», Historia y Memoria de la Educación 7 (2018): 573-613. Dolores Carrillo Gallego y Josefa Dólera Almaida, «Los catálogos de material y la historia de la educación matemática». Póster. (XX Simposio de la Sociedad Española de Investigación en Educación Matemática. Universidad de Málaga (España), 2016).
}

${ }^{34}$ Por ejemplo: Dolores Carrillo Gallego, «La representación visual de los ábacos en los catálogos de material de enseñanza», en Imagen y educación. Marketing, comercialización y didáctica (España, siglo XX), eds. Pedro Luis Moreno y Antonio Viñao, (Madrid: Morata, 2017), 145-154; Dolores Carrillo Gallego, Antonio Maurandi López, y Pilar Olivares Carrillo, «El material de matemáticas en el catálogo de Dalmau Carles, Pla (1935)». Póster. (IV Congreso Iberoamericano de Historia de la Educación Matemática. Universidad de Murcia (España), 2017); Dolores Carrillo Gallego, Antonio Maurandi López, y Pilar Olivares Carrillo, «Los juegos decrolyanos en los catálogos de material en España (1920-1936)», (Oporto: ISCHE, 2019): 20-21.

35 Vera Lucia Gaspar da Silva, «Objetos en viaje: discursos pedagógicos acerca del suministro material de la escuela primaria (Brasil y Portugal, 1870-1920)», Revista Brasileira de História da Educação, Campinas-SP 13, no. 3 (2013): 207-233. 
En el CEME se exponen vitrinas con diversos materiales didácticos. Si bien es cierto que, a diferencia de lo que ocurre con materiales asociados a otras disciplinas, como las ciencias experimentales, en el caso de las matemáticas la mayor parte son reproducciones actuales, hay no obstante que destacar que los materiales expuestos —elaborados muchas veces con motivo de alguna de las exposiciones realizadas y exhibidos temporalmente en el CEME - se han elaborado a partir de documentos textuales y gráficos de la época correspondiente y reproducen fielmente materiales históricos diseñados para la enseñanza y el aprendizaje de las matemáticas, que forman parte de propuestas didácticas analizadas en trabajos publicados por investigadores de este centro.

Cuadernos escolares. Antonio Viñao destaca las ventajas de los cuadernos escolares frente al libro de texto para "conocer y estudiar esa "caja negra" de [...] la realidad y las prácticas escolares, el día a día, [...] lo que sucede, en definitiva, en las aulas cuando el profesor cierra la puerta»;36 los cuadernos escolares constituyen, así, una importante aproximación al saber realmente enseñado y al saber aprendido.

Esta idea ya está presente en profesores normalistas en el primer tercio del siglo XX, cuando los llamados «cuadernos de rotación»o «cuadernos de clase» eran un dispositivo didáctico considerado renovador y usado no solo en la escuela sino en la formación de maestros. Algunos, como Pedro Chico y Eyaralar, este último profesor de matemáticas, consideran los cuadernos de una promoción como un medio que proporciona información sobre el trabajo realizado y que, en consecuencia, puede servir de instrumento de evaluación del trabajo del profesor y, a la vez, para compartir con colegas la experiencia real de una clase, aspecto este relacionado con la formación permanente. De cara a la investigación los cuadernos son un instrumento que aporta información, sobre los saberes mencionados, y también sobre los conocimientos didácticos del profesor. ${ }^{37}$

Se está realizando un estudio sobre los cuadernos escolares de matemáticas existentes en el fondo del CEME. Con motivo de la exposición sobre cuadernos escolares titulada «Los cuadernos escolares: entre el

\footnotetext{
36 Viñao, «Los cuadernos escolares como fuente», 19.

37 Sánchez-Jiménez, «Las Escuelas Normales».
} 
texto y la imagen», realizada por el CEME en 2017, se ha estudiado uno de ellos, un «libro de la clase» de un aula freinetiana, realizado en una escuela murciana, que ha permitido un acercamiento al funcionamiento real de dicha escuela. ${ }^{38}$

Archivos personales. El CEME dispone de archivos personales de algunos maestros, algunos bastante amplios como los de Félix Martí Alpera y María Maroto; otros con menor volumen documental. En lo que se refiere a la HEM, con este material se espera conocer, en casos concretos, la planificación de la enseñanza de las matemáticas en la escuela primaria. Félix Martí Alpera escribió libros de texto de matemáticas que fueron un referente en su época (y después). Precisamente Martí Alpera puede considerarse un mediador cultural entre las ideas pedagógicas de su época y los maestros, y los fondos disponibles en el CEME posibilitan el análisis de esa transposición en particular para el caso de las matemáticas. El legado de María Maroto permite indagar en cómo era la enseñanza de las matemáticas en la escuela aneja a la Normal de Murcia, de la que fue directora.

La posibilidad que ofrecen los fondos del CEME para la investigación en historia de la educación matemática, lo mismo que en la historia de otras disciplinas y, en general, en historia de la educación, está estrechamente vinculada a una adecuada catalogación. Esta tarea constituye una labor importante de entre las que se llevan a cabo en el CEME. Para ello el centro cuenta con el asesoramiento de la Biblioteca General de la Universidad de Murcia, lo que facilita el conocimiento del material disponible y su consulta por parte de cualquier investigador, y nos acerca al propósito de convertir el CEME en un centro de referencia para la investigación histórica en general y sobre historia de la educación matemática en particular.

El Centro de Estudios sobre la Memoria Educativa de la Universidad de Murcia «pretende fomentar la salvaguarda, el estudio y la difusión de la memoria y el patrimonio histórico-educativo de las instituciones educativas de la Región de Murcia». Como se ha comentado, estas finalidades se concretan en cuatro líneas de actuación prioritaria: a) actividades de carácter científico como la realización de investigaciones sobre la cultura material e inmaterial de las instituciones educativas y sus protagonistas;

\footnotetext{
${ }^{38}$ Carrillo y Sánchez, «El "cálculo vivo”»; Carrillo, «Los cuadernos escolares».
} 
b) actividades académicas y formativas, fundamentalmente en el ámbito de la Universidad de Murcia; c) la salvaguarda del patrimonio histórico-educativo de la región de Murcia y d) actividades de carácter museográfico en los locales de los que dispone. Su funcionamiento ha permitido la creación de fondos documentales de diverso tipo como el de manuales escolares, el de catálogos de casas comerciales relacionadas con la educación, el de cuadernos escolares, el de fotografías, el fondo de postales, además de los objetos de diverso tipo relacionados con la educación y el fondo documental que incluye grabaciones audiovisuales que recogen la memoria de los docentes. y una colección de archivos personales de antiguos docentes que se encuentra que se encuentra depositada en el archivo universitario.

La investigación en Historia de la Educación Matemática que están llevando a cabo algunos de sus miembros se enriquece con la utilización de esos fondos que permiten una mirada amplia e integradora a las cuestiones que se plantean en el ámbito de la HEM, desde un nivel legislativo e institucional hasta las planificaciones de aula, los manuales utilizados, el material didáctico y su uso, el reflejo de la actividad de profesores y alumnos en los cuadernos..., la intrahistoria de la educación matemática.

\section{Nota sobre los autores}

Dolores Carrillo Gallego es Licenciada en Ciencias Matemáticas por la Universidad de Zaragoza y Licenciada y Doctora en Pedagogía por la Universidad de Murcia. En la actualidad es profesora titular del Área de conocimiento «Didáctica de las Matemáticas», y su docencia ha estado dirigida a la formación del profesorado en ese ámbito.

Sus líneas de investigación prioritarias son la Historia de la Educación Matemática y la Didáctica de las Matemáticas en la Educación Infantil. Ha sido subdirectora de la Escuela de Magisterio de la Universidad de Murcia y vicedecana de la Facultad de Educación. Es miembro del Centro de Estudios sobre la Memoria Educativa (CEME) de la Universidad de Murcia desde su fundación y forma parte del equipo que gestiona el funcionamiento del Museo Virtual de Historia de la Educación (MUVHE). Ha sido secretaria del CEME (2013-2017) y, en la actualidad, es directora del mismo. 
Pedro Luis Moreno Martínez es Catedrático de Universidad del Departamento de Teoría e Historia de la Educación de la Facultad de Educación de la Universidad de Murcia. Sus líneas de investigación se centran en la historia de la educación en la España contemporánea, la educación popular y de personas adultas, el patrimonio histórico-educativo, la renovación educativa, la educación social, la infancia o el higienismo, sobre las que ha participado en diferentes proyectos de investigación patrocinados por entidades, fundaciones e instituciones regionales, nacionales y europeas y ha publicado numerosos trabajos, monografías y artículos científicos. Ha sido Director del Centro de Estudios sobre la Memoria Educativa (CEME) de dicha Universidad, entre 2013 y 2017, vocal de la Junta Directiva de la Sociedad Española de Historia de la Educación (SEDHE), de 2005 a 2009, y Vicepresidente de la misma de 2009 a 2013, y viene desempeñando el cargo de Vicepresidente de la Sociedad Española para el Estudio del Patrimonio Histórico-Educativo (SEPHE) desde noviembre de 2012 hasta el momento presente. Asimismo, es miembro del Museo Virtual de Historia de la Educación (MUVHE) e investigador principal del Grupo de Investigación E050-03 «Educación, Historia y Sociedad» de la Universidad de Murcia.

Encarna Sánchez Jiménez es Licenciada en Ciencias Matemáticas por la Universidad de Murcia y Doctora en Pedagogía por la misma universidad. En la actualidad es profesora titular de Universidad del Área de conocimiento «Didáctica de las Matemáticas», y su docencia ha estado dirigida a la formación del profesorado de educación infantil primaria y secundaria en ese ámbito.

Sus líneas de trabajo e investigación se centran en Didáctica de la Matemática (Teoría Antropológica de lo Didáctico, Formación de profesores; Resolución de problemas) e Historia de la Educación Matemática.

Ha sido subdirectora académica de la Escuela de Magisterio de la Universidad de Murcia y directora del Dpto. de Didáctica de las Ciencias Matemáticas y Sociales. Coordina la especialidad de Matemáticas del Máster en Formación del Profesorado de Secundaria Obligatoria y Bachillerato. Es miembro del Centro de Estudios sobre la Memoria Educativa (CEME) de la Universidad de Murcia desde su fundación. Es miembro de la Junta Directiva de la Sociedad de Educación Matemática de la 
Región de Murcia (SEMRM). Ha coordinado la organización de concursos de matemáticas dirigidos a estudiantes de primaria, secundaria y estudios de grado universitarios. Está implicada en programas de movilidad internacional y ha sido promotora de varios convenios con instituciones latinoamericanas relacionadas con la formación de maestros.

\section{REFERENCIAS}

Bernal Martínez, José Mariano y José Damián López Martínez. «La Junta para Ampliación de Estudios (JAE) y la enseñanza de la ciencia para todos en España». Revista de Educación, número extraordinario (2007): 215-239.

Bernal Martínez, J. Mariano y J. Damián López Martínez. «Los museos educativos y el material científico-pedagógico construido en la escuela». En La cultura material de la escuela. En el centenario de la Junta para Ampliación de Estudios, 1907-2007, editado por Agustín Escolano Benito, 155-168. Berlanga de Duero: Centro Internacional de la Cultura Escolar, 2007.

Bernal Martínez, J. Mariano, J. Damián López Martínez y Pedro L. Moreno Martínez. «Museos pedagógicos y enseñanza de las ciencias: de las láminas y colecciones a los recursos didácticos virtuales». En I Encontro Iberoamericano de Museos Pedagóxicos e Museólogos da educación. Actas, 413-425. Santiago de Compostela: Xunta de Galicia, MUPEGA, 2008.

Bernal Martínez, J. Mariano y J. Damián López Martínez. El patrimonio científico de los institutos de enseñanza secundaria. Un recurso didáctico en las Ciencias para el mundo contemporáneo. Madrid: UNED ediciones, 2009.

Bernal Martínez, J. Mariano, Ma Ángeles Delgado Martínez y J. Damián López Martínez. «El patrimonio histórico-científico como recurso didáctico: de las ciencias de laboratorio a las ciencias para la vida». En El largo camino hacia una Educación Inclusiva. La Educación Especial y Social del siglo XIX a nuestros días, coordinado por M.Reyes Berruezo Albéniz y Susana Conejero López, 605-614. Pamplona: Universidad Pública de Navarra, 2009.

Bernal Martínez, J. Mariano y J. Pedro Marín Murcia. «José Loustau y la Universidad de Murcia (1916-1965): el desarrollo de la competencia profesional y la promoción de la educación científica». En Arte y oficio de enseñar. Dos siglos de perspectiva histórica, editado por Pablo Celada Perandones, 287-294 (vol. I). El Burgo de Osma: Sociedad Española de Historia de la Educación, Universidad de Valladolid y Centro Internacional de la Cultura Escolar, 2011.

Bernal Martínez, J. Mariano y José Pedro Marín Murcia. «El estudio del material científico para el estudio de la Botánica en el CEME». En Patrimonio y etnografía de la escuela en España y Portugal durante el siglo XX, editado por 
Pedro L. Moreno Martínez y Ana Sebastián Vicente, 157-166. Murcia: SEPHE-CEME, 2012.

Burgos-Risco, Alfonso y María J. Martínez-Ruiz. «La memoria de las manos. La realización de un documental de historia de la educación». Arte, Individuo y Sociedad 31, no. 2 (2019): 345-359.

Carrillo, Isabel, Eulàlia Colleldemont y Pedro L. Moreno. «El patrimoni educatiu, element d'una pedagogia cultural i ciutadana». Temps d'Educació 35 (2008): 277-290.

Carrillo Gallego, Dolores. «La Metodología de la aritmética en los comienzos de las Escuelas Normales (1838-1868) y sus antecedentes». PhD diss., Universidad de Murcia, 2005.

Carrillo Gallego, Dolores. "Vallejo y la iniciación aritmética en las escuelas». En: José Mariano Vallejo, el matemático ilustrado. Una mirada desde la educación matemática, editado por Alexander Maz, Manuel Torralbo y Luis Rico, 25-47. Córdoba: Servicio de Publicaciones de la Universidad de Córdoba, 2006.

Carrillo Gallego, Dolores y Encarna Sánchez Jiménez. «Aprender matemáticas jugando: la propuesta educativa de Eyaralar». En La cultura material de la escuela. En el centenario de la Junta para la Ampliación de Estudios, 19072007, editado por Agustín Escolano, 183-194. Berlanga de Duero (Soria): CEINCE, 2007.

Carrillo Gallego, Dolores y Encarna Sánchez Jiménez. «El material de enseñanza en las praxeologías de formación de maestros en España (1920-1936)». En IV Congrès International sur la TAD. Toulouse: IUFM de l'Academie de Toulouse (France), 2013.

Carrillo Gallego, Dolores y Encarna Sánchez Jiménez. «Propuestas de uso de los instrumentos de dibujo para la enseñanza de la geometría en la Edad de Plata». En Pedagogía museística. Prácticas, usos didácticos e investigación del patrimonio educativo, coordinado por Ana M. Badanelli, María Poveda Sanz y Carmen Rodríguez. Madrid: Universidad Complutense de Madrid, 2014.

Carrillo Gallego, Dolores y Josefa Dólera Almaida. «Los catálogos de material y la historia de la educación matemática». Póster. XX Simposio de la Sociedad Española de Investigación en Educación Matemática. Universidad de Málaga (España), 2016.

Carrillo Gallego, Dolores et al. Los cuadernos escolares: entre el texto y la imagen. Murcia: edit.um, 2017.

Carrillo Gallego, Dolores. «La representación visual de los ábacos en los catálogos de material de enseñanza». En Imagen y educación. Marketing, comercialización y didáctica (España, siglo XX), editado por Pedro Luis Moreno y Antonio Viñao, 145-154. Madrid: Morata, 2017. 
Carrillo Gallego, Dolores y Encarna Sánchez Jiménez. «El “cálculo vivo” en un cuaderno freinetiano». HISTEMAT 3, no. 3 (2017): 40-54.

Carrillo Gallego, Dolores, Antonio Maurandi López, y Pilar Olivares Carrillo. «El material de matemáticas en el catálogo de Dalmau Carles, Pla (1935)». Póster. IV Congreso Iberoamericano de Historia de la Educación Matemática. Universidad de Murcia (España), 2017.

Carrillo, Dolores, José Manuel Matos, Pedro Luis Moreno, Encarna Sánchez-Jiménez y Wagner R. Valente. IV Congreso Iberoamericano de Historia de la Educación Matemática. Actas. Murcia-España: Centro de Estudios sobre la Memoria Educativa. Universidad de Murcia, 2018.

Carrillo Gallego, Dolores, Antonio Maurandi López, y Pilar Olivares Carrillo. «Los juegos decrolyanos en los catálogos de material en España (19201936)». 20-21. Oporto: ISCHE, (2019).

Cerdá Mondéjar, Carmen M. «Sobre la celebración de la Fiesta del Árbol en la Región de Murcia: espacio de propaganda política o reflejo de valores educativos». En Espacios y patrimonio histórico-educativo, coordinado por Paulí Dávila Balsera y Luis $\mathrm{M}^{\mathrm{a}}$ Naya Garmendia, 541-554. Donostia: Erein, 2016.

Chaachoua, Hamid y Claude Comiti. «L'analyse du rôle des manuels dans l'approche anthropologique». En II Congrés International su la Théorie Antropologique du Didactique, 137-151.Uzés, 2007.

Da Silva, Vera Lucia Gaspar. «Objetos en viaje: discursos pedagógicos acerca del suministro material de la escuela primaria (Brasil y Portugal, 18701920)». Revista Brasileira de História da Educação. Campinas-SP 13, no 3 (2013): 207-233.

Delgado Martínez, $\mathrm{M}^{\mathrm{a}}$ Ángeles et al., «El material científico del Instituto Local de Lorca (siglo XIX): recuperación y difusión a través del Museo Virtual de Historia de la Educación». En I Encontro Iberoamericano de Museos Pedagóxicos e museólogos da educación. Actas, 531-543. Santiago de Compostela: Xunta de Galicia, MUPEGA, 2008.

Delgado Martínez, Ma Ángeles et al., El Gabinete de Física del Instituto de Lorca (1864-1883): guía didáctica. Murcia: Servicio de Publicaciones Consejería de Educación, Formación y Empleo de la Región de Murcia, 2010.

Delgado Martínez, Ma Ángeles y J. Damián López Martínez, «Dr. Camps (Margarita Comas): una maestra en el exilio». En Arte y oficio de enseñar. Dos siglos de perspectiva histórica, editado por Pablo Celada Perandones, 605614 (vol. I). El Burgo de Osma: Sociedad Española de Historia de la Educación, Universidad de Valladolid y Centro Internacional de la Cultura Escolar, 2011.

Delgado Martínez, Ma Ángeles y J. Damián López Martínez. «Los diarios del alumnado de la Escuela Normal de Magisterio de Murcia (1931-1933) como 
muestra de la práctica y el quehacer diario en las clases de Primitiva López». En Patrimonio y etnografía de la escuela en España y Portugal durante el siglo XX, editado por Pedro L. Moreno Martínez y Ana Sebastián Vicente, 419. 434. Murcia: SEPHE-CEME, 2012.

López Martínez, J. Damián. «Francia en el punto de mira: el material científico para la enseñanza de la física y química en los institutos de segunda enseñanza a partir del Plan de 1845». En Influencias francesas en la educación española e iberoamericana (1808-2008), editado por J. M ${ }^{\mathrm{a}}$ Hernández Díaz, 147-159. Salamanca: Gobalia ediciones Anthema, 2008.

López Martínez, J. Damián. «Divulgación de la cultura científica a través del patrimonio histórico-científico del Centro de Estudios sobre la Memoria Educativa». En Memoria, ciudadanía y Museos de educación, coordinado por Eulalia Colleldemont, Nuria Padrós e Isabel Carrillo, 119-130. Vic: Universidad de Vic, 2010.

López Martínez, J. Damián (coords). Las ciencias en la escuela. El material científico y pedagógico de la Escuela Normal de Murcia. Murcia: Editum, 2012.

López Martínez, J. Damián. Aurelio Rodríguez Charentón, un maestro en el olvido. Murcia: Editum, 2014.

López Martínez, J. Damián. «Construir una imagen de la ciencia: las ilustraciones de los libros escolares de lecturas científicas». En Actas del XVIII Coloquio de historia de la Educación. Arte, Literatura y educación, editadas por Nuria Padrós, Eulalia Colleldemont y J. Soler, 125-138. Vic: Servicio de publicaciones de la Universitat de Vic, 2015.

López Martínez, J. Damián et al. «Patrimonio, cultura material e innovación docente: Propuestas y experiencias». Educació i Història: Revista d'Història de l'Educació 26 (2015): 89-120.

López Martínez, J. Damián y J. Mariano Bernal Martínez. «La Revista de Pedagogía como fuente de información sobre el material científico-didáctico escolar». En Museos pedagógicos. La memoria recuperada, editado por Víctor Juan, 351- 366. Huesca: Gobierno de Aragón-Museo Pedagógico de Aragón, 2008.

López Martínez, J. Damián y J. Mariano Bernal Martínez. «El material de enseñanza como recurso didáctico en la Historia de la Educación». En El Patrimonio histórico-educativo y la enseñanza de la Historia de la Educación, 5392. Murcia: Sociedad Española de Historia de la Educación, 2009.

López Martínez, J. Damián y Mª José Martínez Ruiz-Funes. «Análisis de cuadernos escolares producidos por casas editoriales de ciencias experimentales». En Espacios y patrimonio histórico-educativo, coordinado por Paulí Dávila y Luis M. ${ }^{a}$ Naya, 1.053-1.073. Donostia: Erein, 2016.

López Martínez, J. Damián y Luisa López Banet. «Cotos escolares: espacios educativos para la enseñanza de las ciencias en la escuela española del siglo XX». Bordón 69, no. 3 (2017): 161-174. 
Mahamud, Kira y M. José Martínez Ruiz-Funes. «Reconstructing the life histories of Spanish primary school teachers: a novel approach for the study of the teaching profession and school culture». History of Education 46, no. 3 (2014): 793-819.

Margolinas, Claire y Floriane Wozniak. «Usage des manuels dans le travail de l'enseignant: l'enseignement des mathématiques à l'école primaire». Revue des sciences de l'éducation 35, no. 2 (2009): 59-82.

Martínez Ruiz-Funes, María José. «El material froebeliano en España en la segunda mitad del siglo XIX». En Influencias alemanas en la educación española e iberoamericana (1809-2009), editado por J. M ${ }^{\mathrm{a}}$ Hernández Díaz, 153 166. Salamanca: Globalia ediciones Anatema, 2009.

Martínez Ruiz-Funes, María José, Pedro L. Moreno Martínez y Ana Sebastián Vicente. "Los catálogos de material de enseñanza como recurso didáctico». En Genealogía y desarrollo del sistema educativo liberal, editado por Gloria Espigado Tocino et al., 867-877. Cádiz: Universidad de Cádiz, 2013.

Martínez-Valcárcel, Nicolás (dir.). La construcción de los recuerdos escolares de Historia de España en Bachillerato (1993-2013). Análisis, interpretación y poder de cambio de los testimonios de profesores y alumnos. Valencia: Nau Llibres, 2014.

Martínez-Valcárcel, Nicolás y Ramón García. El patrimonio enseñado: plataforma para el desarrollo del turismo responsable. Base de Datos 2013-2014. Murcia: Diego Marín, 2016.

Martínez-Valcárcel, Nicolás. «El uso del libro de texto de Historia de España en bachillerato». Revista Historia da Educação 20, no. 50 (2016): 69-93.

Meda, Juri y Antonio Viñao. "School Memory: Historiographical Balance and Heuristcs Perspectives». En School Memories. New Trends in the History of Education, editado por Cristina Yanes-Cabrera, Juri Meda y Antonio Viñao. New York: Springer, 2017.

Moreno Martínez, Pedro Luis. «El mobiliario escolar en los catálogos de material de enseñanza: consideraciones metodológicas». En La infancia en la Historia: espacios y representaciones, coordinado por Paulí Dávila y Luis M. ${ }^{a}$ Naya, 342-355. Donostia: Erein, 2005.

Moreno Martínez, Pedro Luis. "History of School Desk Development in Terms of Hygiene and Pedagogy in Spain (1838-1936)». En Materialities of Schooling. Design - Techology - Objects - Routines, editado por Martin Lawn y António Nóvoa, 71-95. Oxford: Symposium Books, 2005.

Moreno Martínez, Pedro Luis. «The Hygienist Movement and the Modernization of Education in Spain». Paedagogica Historica. International Journal of the History of Education 42, no. 6 (2006): 793-815.

Moreno Martínez, Pedro Luis. «La modernización de la cultura material de la escuela pública en España, 1882-1936». En La cultura material de la escuela. 
En el centenario de la Junta para Ampliación de Estudios, 1907-2007, editado por Agustín Escolano Benito, 45-74. Berlanga de Duero: Centro Internacional de la Cultura Escolar, 2007.

Moreno Martínez, Pedro Luis. «El aula en el recuerdo: biografía, memoria y cultura material de la escuela primaria en España, 1900-1970». En Museos Pedagógicos. La memoria recuperada, editado por Víctor Juan, 95-108. Huesca: Museo Pedagógico de Aragón, 2008.

Moreno Martínez, Pedro Luis. "La Historia de la educación como disciplina y campo de investigación: renovación historiográfica, patrimonio y educación». En El largo camino hacia una educación inclusiva. Aportaciones desde la Historia de la Educación, coordinado por Reyes Berruezo, 141-151. Pamplona: Universidad Pública de Navarra, 2009.

Moreno Martínez, Pedro Luis. «Els museus virtuals d'educació com a pedagogia». Butlletí MUVIP 1 (2009): 11-16.

Moreno Martínez, Pedro Luis. Félix Martí Alpera (1875-1946): un maestro y la escuela de su tiempo. Murcia: Ediciones de la Universidad de Murcia, 2010.

Moreno Martínez, Pedro Luis. «Presentación». Educatio Siglo XXI 28, no. 2 (2010): 9-15.

Moreno Martínez, Pedro Luis. «Las Memorias de Félix Martí Alpera». En Martí Alpera, Félix: Memorias, edición y estudio introductorio de Pedro L. Moreno, I-XXXII. Murcia: Ediciones de la Universidad de Murcia, 2011.

Moreno Martínez, Pedro Luis. «El Museo Pedagógico Nacional y la modernización educativa en España (1882-1941)». En La Institución Libre de Enseñanza y Francisco Giner de los Ríos: nuevas perspectivas. 2. La Institución Libre de Enseñanza y la cultura española, editado por José García Velasco y Antonio Morales Moya, 458-475. Madrid: Fundación Francisco Giner de los Ríos [Institución Libre de Enseñanza] - Acción Cultural Española, 2012.

Moreno Martínez, Pedro Luis y Ana Sebastián Vicente. «Los catálogos de material de enseñanza y la cultura material de la escuela. La colección del Centro de Estudios sobre la Memoria Educativa (CEME) de la Universidad de Murcia». En Patrimonio y etnografía de la escuela en España y Portugal durante el siglo XX, editado por Pedro L. Moreno Martínez y Ana Sebastián Vicente, 293-309. Murcia: SEPHE-CEME, 2012.

Moreno Martínez, Pedro Luis. «Rosa Sensat, la cultura material de l'escola i el material d'ensenyament». Temps d'Educació 44 (2013): 77-99.

Moreno Martínez, Pedro Luis y José Pedro Marín Murcia. «La casa comercial Cultura y la oferta de Material Pedagógico Moderno en España (19241934)». En Pedagogía museística. Prácticas, usos didácticos e investigación del patrimonio educativo, coordinado por Ana M. Badanelli, María Poveda Sanz y Carmen Rodríguez, 523-531. Madrid: Universidad Complutense de Madrid, 2014. 
Moreno Martínez, Pedro Luis. «Las Jornadas Científicas de la Sociedad Española para el Estudio del Patrimonio Histórico-Educativo (SEPHE) y el avance del conocimiento». En Memoria de la educación. El legado pedagógico de Julio Ruiz Berrio, editado por Carmen Colmenar y Teresa Rabazas, 281-303. Madrid: Biblioteca Nueva, 2015.

Moreno Martínez, Pedro Luis. «El Centro de Estudios sobre la Memoria Educativa (CEME) de la Universidad de Murcia: una aventura académica en curso». Cabás - Revista digital sobre el Patrimonio Histórico-Educativo 14 (2015): 173-187. URL: http://revista.muesca.es/centrosphe14/351-ceme

Moreno Martínez, Pedro Luis. «El Museo Virtual de Historia de la Educación (MUVHE) y el Centro de Estudios sobre la Memoria Educativa (CEME) de la Universidad de Murcia». En Los Museos Pedagógicos en España. Entre la memoria y la creatividad, coordinado por Pablo Álvarez Domínguez, 175188. Gijón - Sevilla: Trea - Editorial Universidad de Sevilla, 2016.

Moreno Martínez, Pedro Luis y Antonio Viñao (coords.). Imagen y educación. Marketing, comercialización, didáctica (España, siglo XX). Madrid: Morata, 2017.

Moreno Martínez, Pedro Luis. "Memoria escolar y patrimonio educativo». En Educación, historia y sociedad. El legado historiográfico de Antonio Viñao, editado por Pedro L. Moreno Martínez, 408-415. Valencia: Tirant, 2018.

Moreno Martínez, Pedro Luis. «El Museo Pedagógico Nacional: un laboratorio para la formación del magisterio». En Laboratorio de la Nueva Educación. En el centenario del Instituto-Escuela, editado por Belén Alarcó, 408-415. Madrid: Fundación Francisco Giner de los Ríos [Institución Libre de Enseñanza], 2019.

Sánchez Jiménez, Encarna. «La resolución de problemas: aportaciones de Aurelio Rodríguez Charentón». En Arte y oficio de enseñar. Dos siglos de perspectiva histórica, editado por Pablo Celada Perandones, 507-516. El Burgo de Osma: Sociedad Española de Historia de la Educación, Universidad de Valladolid y Centro Internacional de la Cultura Escolar, 2011, 2 vols.

Sánchez Jiménez, Encarna. «Las Escuelas Normales y la renovación de la enseñanza de las matemáticas (1909-1936)». PhD diss., Universidad de Murcia, 2015.

Sebastián Vicente, Ana. «Los manuales escolares: cultura material de la escuela y fuente para la historia de la educación. Un análisis de los libros de lectura para adultos neolectores durante las campañas de alfabetización del franquismo». En Museos Pedagógicos. La memoria recuperada, editado por Víctor Juan, 207-220. Huesca: Museo Pedagógico de Aragón, 2008.

Sebastián Vicente, Ana. «Los espacios educativos en la educación de personas adultas. Una aproximación a través de las imágenes de los cuadernos escolares». En Espacios y patrimonio histórico-educativo, coordinado por Paulí 
Dávila Balsera y Luis $\mathrm{M}^{\mathrm{a}}$ Naya Garmendia, 1.101-1.114. Donostia: Erein, 2016.

Terrón Bañuelos, Aida. «El profesorado. Autobiografías, memorias y diarios». En Educación, historia y sociedad. El legado historiográfico de Antonio Viñao, editado por Pedro L. Moreno Martínez, 355-383. Valencia: Tirant, 2018. Viñao, Antonio. «The School Head's Office as Territory and Place: location and physical layout in the first Spanish graded schools». En Materialities of Schooling. Design - Techology - Objects - Routines, editado por Martin Lawn y António Nóvoa, 47-70. Oxford: Symposium Books, 2005.

Viñao, Antonio. "La memoria escolar: restos y huellas, recuerdos y olvidos». Annali di Storia dell'Educazione e delle Istituzioni Scholastiche 12 (2005): 19-33.

Viñao, Antonio. «Historia y educación: memorias, olvidos y silencios (bases para la creación de un centro de memoria educativa)». En Jornada de Homenaje al maestro del Consejo Escolar de la Región de Murcia, 69-90. Murcia: Consejería de Educación y Cultura, Consejo Escolar, 2005.

Viñao, Antonio. «Templos de la patria, templos del saber. Los espacios de la escuela y la arquitectura escolar». En Historia ilustrada de la escuela en España. Dos siglos de perspectiva histórica, dirigida por Agustín Escolano, 47-71. Madrid: Fundación Germán Sánchez Ruipérez, 2006.

Viñao, Antonio. "El espacio escolar: viejas cuestiones, nuevos escenarios». En Historia ilustrada de la escuela en España. Dos siglos de perspectiva histórica, dirigida por Agustín Escolano, 289-308. Madrid: Fundación Germán Sánchez Ruipérez, 2006.

Viñao, Antonio. "Los cuadernos escolares como fuente histórica: aspectos metodológicos e historiográficos». Annali di Storia dell'Educazione e delle Istituzioni Scholastiche 13 (2006): 17-35.

Viñao, Antonio. "La escuela y sus escenarios en la España del siglo XX: el espacio y la arquitectura escolar». En La escuela y sus escenarios, editado por Juan Gómez Fernández, Gloria Espigado Tocino y Miguel Beas Miranda, 9-36. El Puerto de Santa María: Concejalía de Cultura del Ayuntamiento de El Puerto de Santa María, 2007.

Viñao, Antonio. "Memoria escolar y Guerra Civil. Autobiografías, memorias y diarios de maestros y maestras». Cultura Escrita \& Sociedad 4 (2007): 171202.

Viñao, Antonio. «Memoria, patrimonio y educación». Educatio Siglo XXI 28, no. 2 (2010): 17-42

Viñao, Antonio. "Ayer y hoy de la educación en España: memorias y desmemorias». En Lecciones contra el olvido. Memoria de la educación y educación de la memoria, coordinado por Carlos Lomas, 23-60. Barcelona: Octaedro, 2011. 
Viñao, Antonio. «El patrimonio histórico-educativo: memoria, nostalgia y estudio». Con-Ciencia Social 15 (2011): 141-147.

Viñao, Antonio. «Teacher's Egodocuments as a Source of Classroom History. The Case of Autobiographies, Memoirs and Diaries». En The Black Box of Schooling. A Cultural History of the Classroom, editado por Sjaak Braster, Ian Grosvenor y $\mathbf{M}^{\mathrm{a}}$ del Mar del Pozo, 141-157. Bruxelles: P.I.E. Peter Lang, 2011.

Viñao, Antonio y María José Martínez Ruiz Funes, «Los cuadernos escolares y el arte de enseñar: el fondo del Centro de Estudios sobre la Memoria Educativa (CEME) de la Universidad de Murcia». En Arte y oficio de enseñar. Dos siglos de perspectiva histórica, editado por Pablo Celada Perandones, 245-254 (vol. I). El Burgo de Osma: Sociedad Española de Historia de la Educación, Universidad de Valladolid, Centro Internacional de la Cultura Escolar, 2011.

Viñao, Antonio. «El MUVHE y el CEME como pre-texto: reflexiones sobre la protección, conservación, estudio y difusión del patrimonio histórico-educativo». En Patrimonio y Etnografía de la escuela en España y Portugal durante el siglo $X X$, editado por Pedro L. Moreno Martínez y Ana Sebastián Vicente, 639. Murcia: Sociedad Española para el Estudio del Patrimonio Histórico-Educativo (SEPHE) y Centro de Estudios sobre la Memoria Educativa (CEME) de la Universidad de Murcia, 2012.

Viñao, Antonio. «Historia de las disciplinas, profesionalización docente y formación de profesores: el caso español». Pro-Posiçoes 23 (2012): 103118.

Viñao, Antonio. «La historia de las disciplinas escolares en España: una revisión con especial atención a la educación secundaria». En Aulas con memoria. Ciencia, educación y patrimonio en los Institutos históricos de Madrid (1837-1936), editado por Leoncio López Ocón, Santiago Aragón y Mario Pedrazuela, 265-277. Madrid: CEIMES, CSIC y Comunidad de Madrid, 2012.

Viñao, Antonio. "Balance de la investigación sobre cuadernos escolares en España». En La historia de la cultura escolar en Italia y España: balance y perspectivas, editado por Juri Meda y Ana Badanelli, 63-82. Macerata: Edizioni Università di Macerata (EUM), 2013.

Viñao, Antonio. «El Libro escolar». En Historia de la edición en España 19391975, dirigido por Jesús A. Martínez Martín, 681-698. Madrid: Marcial Pons Historia, 2015.

Viñao, Antonio. «El espacio escolar ¿Cómo abordar un objeto polifacético y multiforme?». En Espacios y patrimonio histórico-educativo, coordinado por Paulí Dávila Balsera y Luis M $^{a}$ Naya Garmendia, 25-59. Donostia: Erein, 2016. 


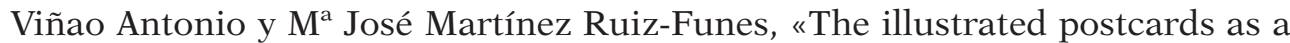
tool of construction and reconstruction of the school memory (Spain, 19th20th century)». En School memories. New trends in the history of education research, editado por Juri Meda, Cristina Yanes y Antonio Viñao, 29-46. New York: Springer, 2016.

Viñao, Antonio, M. ${ }^{a}$ José Martínez Ruiz-Funes y Pedro L. Moreno Martínez. Tarjeta postal ilustrada y educación (España, siglos XIX-XX). Murcia: edit.um, 2016. 